\section{(A) Check for updates}

Cite this: Polym. Chem., 2019, 10 6447

Received 30th July 2019,

Accepted 14th October 2019

DOI: 10.1039/c9py01133a

rsc.li/polymers

\title{
Controlled synthesis of methacrylate and acrylate diblock copolymers via end-capping using CCTP and FRP $\uparrow$
}

\author{
Georgios Patias, (D) Alan M. Wemyss, (iD Spyridon Efstathiou, James S. Town, \\ Christophe J. Atkins, (D) Ataulla Shegiwal, (D) Richard Whitfield (D) and \\ David M. Haddleton (iD *
}

\begin{abstract}
Scalable methods of producing functional materials is of importance. Herein, we report the use of free radical copolymerisation of $\omega$-unsaturated methacrylic macromonomers, as derived from catalytic chain transfer polymerisation (CCTP), with acrylic monomers in solution leading to block copolymers by varying the nature of the macromonomer. We demonstrate the effect that varying the molecular weight and ester side chain length of macromonomer from CCTP, has on the polymerisation leading to either graft or diblock copolymers. DOSY NMR, MALDI-TOF/ToF MS has allowed for the exploration of the extent to which varying the concentration of macromonomer has on the products formed. Importantly, during the successful synthesis of acrylic and methacrylic diblock copolymers with broad dispersities of each block, full consumption of the macromonomers was observed.
\end{abstract}

\section{Introduction}

Low molecular weight methacrylic polymers/oligomers bearing propenyl $\omega$-end groups have been used as precursors in the synthesis of a range of materials, such as functionalised branched copolymers, amphiphilic dispersants, or multi-block copolymers. ${ }^{1-8}$ Copolymerisation with acrylates can be challenging and has been the subject of a number of previous investigations. ${ }^{9-13}$ Propagating radicals, as produced from conventional free radical polymerisation, from both of these monomer types have been shown to readily add to the vinyl end groups of these oligomers, and following addition, the relative rates of monomer propagation $\left(k_{\mathrm{p}}\right)$ and beta-scission/ fragmentation of the radical adduct $\left(k_{\beta}\right)$ largely determine the composition of the products. ${ }^{14-19}$

An efficacious method to produce low molecular weight oligomers containing functional unsaturated end groups which has been exploited industrially for over 20 years, is cobalt(II) mediated catalytic chain transfer polymerisation (CCTP). ${ }^{20-27}$ The Co ${ }^{\text {II }}$ catalysts used in CCTP are highly efficient in chain transfer from propagating polymer to cobalt(II) leading to

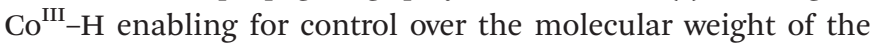
polymers produced at very low catalyst concentrations ( $\mathrm{ppm}$ ). CCTP of methacrylates leads to the abstraction of a hydrogen

University of Warwick, Department of Chemistry, Gibbet Hill, CV4 7AL Coventry, UK. E-mail:d.m.haddleton@warwick.ac.uk

$\dagger$ Electronic supplementary information (ESI) available. See DOI: 10.1039/ c9py01133a atom from the $\alpha$-methyl group relative to the radical centre resulting in a vinyl terminated chain and an unstable $\mathrm{Co}^{\mathrm{III}}-\mathrm{H}$ complex that reinitiates polymerisation through hydrogen transfer to monomer, regenerating the $\mathrm{Co}^{\mathrm{II}}$ catalyst. This is a highly efficient process with observed chain transfer constants over four orders of magnitude higher than thiols at up to $C_{\mathrm{s}}=$ 50 000. Through this process, macromonomers are produced with $\alpha$-hydrogen and $\omega$-vinyl groups (mechanism ESI Fig. $1 \dagger$ ).

We have previously investigated the copolymerisation of methacrylic macromonomers from CCTP with methacrylates. ${ }^{3,12,28,29}$ Following the addition of a propagating polymeric methacrylic radical to the vinyl functionality of these macromonomers, the relative rates of propagation and $\beta$-scission $\left(k_{\mathrm{p}} / k_{\beta}\right)$ is low, hence $\beta$-scission (fragmentation) is favoured. This addition-fragmentation chain transfer (AFCT) process produces a propagating radical of the original macromonomer and a new methacrylic macromonomer that is also capable of undergoing an AFCT reaction. ${ }^{9,12,30}$ In this way, block copolymers can be produced in a process similar to conventional sulphur containing RAFT agents, mediated by dithioester or trithiocarbonate chain transfer agents (CTAs).

In contrast, acrylic monomers generally have higher propagation rate constants than methacrylates. For example, the $k_{\mathrm{p}}$ of methyl methacrylate has been measured as $323 \mathrm{~L} \mathrm{~mol}^{-1} \mathrm{~s}^{-1}$, whereas the $k_{\mathrm{p}}$ of methyl acrylate is nearly fifty times higher at $15600 \mathrm{~L} \mathrm{~mol}^{-1} \mathrm{~s}^{-1} \cdot{ }^{31,32}$ Based upon this, the copolymerisation behaviour of acrylate monomers and these CCTP methacrylic macromonomers is expected to be significantly different, with a number of reports in the literature describing the formation 


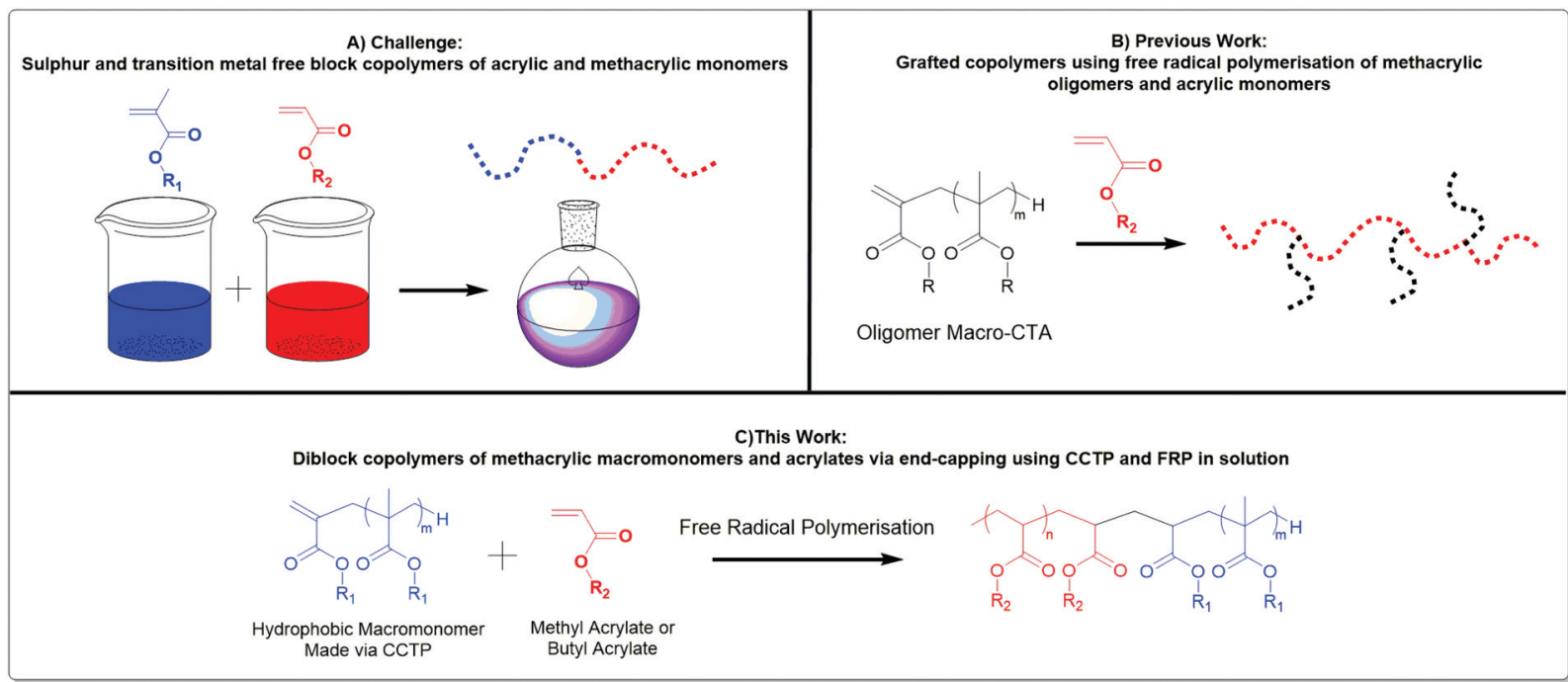

Scheme 1 A) Target is to synthesise AB block copolymers using conventional free radical polymerisation. (B) Oligomers containing terminal vinyl functionality might be expected to copolymerise with acrylates to give graft copolymers. (C) This work demonstrates the formation of $A B$ block copolymers by use of macroCTA agents prepared from catalytic chain transfer polymerisation.

of graft copolymers. ${ }^{33-35}$ However, studies from Yamada and co-workers show that the copolymerisation of acrylates can be much more complicated than suggested in previous studies. $^{13,36-38}$

Herein, we give new insight into the effective copolymerisation of two types of monomers, methacrylates and acrylates, Scheme 1. A better mechanistic understanding of the copolymerisation of methacrylic macromonomers with methacrylates is reported utilising MALDI-ToF/ToF MS. Moreover, the effect of the chain length of methacrylic macromonomers from CCTP into the free radical polymerisation of acrylates is investigated. We have also explored the extent to which the nature of the macromonomer changes the nature of the final product. Grafted polymers were obtained when methyl methacrylate oligomers were present in the methyl acrylate polymerisation, whereas end-capped diblock copolymers of acrylates with pLMA, pBMA, pBzMA were synthesized under similar conditions. Notably, the ${ }^{1} \mathrm{H}$ NMR spectroscopy showed full consumption of the macromonomer and successful synthesis of diblock copolymers with various molecular weights, albeit macromonomers with broad dispersities were used in their free radical copolymerisation with acrylates. This leads to block and graft copolymers without the requirement of transition metal catalysts, sulphur containing RAFT agents or other expensive and often troublesome reagents. This work is focussed on free radical polymerisation which is widely used and accepted.

\section{Experimental section}

\section{Materials and methods}

Reagents and chemicals. Methyl acrylate (MA, $\geq 99 \%$ ), methyl methacrylate (MMA, $\geq 99 \%$ ), butyl methacrylate (BMA, $\geq 99 \%$ ) were purchased from Sigma-Aldrich, lauryl methacrylate (LMA, $\geq 99 \%$ ) was kindly donated by GEO Speciality Chemicals. Initiator V-601 (dimethyl 2,2'-azobis(2-methyl propionate)) was obtained from Wako Chemicals, AIBN $\left(2,2^{\prime}\right.$ azobis(2-methylpropionitrile)) was purchased from SigmaAldich and trigonox-21s (tert-butyl peroxy-2-ethylhexanoate) was obtained from AkzoNobel, deuterated methyl methacrylate $\left(\operatorname{MMAd}_{8}\right)$ was purchased from Cambridge Isotopes Ltd. All of the remaining materials were purchased from Sigma-Aldrich or Fisher Scientific. The catalysts bis[(difluoroboryl)dimethyl glyoximato]cobalt(II) (CoBF) and bis[(difluoroboryl)dimethyl phenyl-glyoximato]cobalt(II) (Co(MePh)BF) were synthesised in our laboratory as described previously. ${ }^{23}$

\section{General procedure for the preparation of methacrylic macromonomers via catalytic chain transfer polymerisation}

For a CCTP in solution, $0.09 \mathrm{mg}$ bis[(difluoroboryl)dimethyl glyoximato]cobalt(II) (CoBF, $5 \mathrm{ppm}$ relative to monomer) for MMA or bis[(difluoroboryl)dimethyl phenyl-glyoximato]cobalt (II) $(\mathrm{Co}(\mathrm{MePh}) \mathrm{BF})$ for BMA, BzMA and LMA and a stirring bar were charged into a $100 \mathrm{~mL}$ round bottom flask. Nitrogen was purged into the flask for 1 minute (ESI Fig. 4b $\dagger$ ). Subsequently, $10 \mathrm{ml}$ of methyl methacrylate (MMA) previously deoxygenated for 30 minutes (ESI Fig. 4a $\dagger$ ), were added to the flask via a deoxygenated syringe. The mixture was stirred under a nitrogen atmosphere until the dissolution of the catalyst. Meanwhile, $107 \mathrm{mg}$ dimethyl 2,2'-azobis(2-methyl propionate) (V601, $1 \mathrm{~mol} \%$ relative to monomer) were dissolved in $10 \mathrm{ml}$ toluene $(1 / 1 \mathrm{v} / \mathrm{v}$ to monomer) and the solution was charged into a $50 \mathrm{~mL}$ round bottom flask and bubbled with nitrogen for $30 \mathrm{~min}$. Subsequently, the $100 \mathrm{~mL}$ flask with the monomer and catalyst was heated to $75{ }^{\circ} \mathrm{C}$ under an inert atmosphere. When the temperature of the catalyst solution 
reached $75{ }^{\circ} \mathrm{C}$, the initiator solution added. The reaction was allowed to continue for 6 hours with continuous stirring.

The number average molecular weight of macromonomers was calculated from ${ }^{1} \mathrm{H}$ NMR spectra by integrating the vinyl resonances (6.17 and $5.44 \mathrm{ppm}$ ) against the methoxy peak (3.57 ppm). ${ }^{1} \mathrm{H}$ NMR (400 MHz, $\mathrm{CDCl}_{3}$ ): $\delta 6.17(\mathrm{~s}, 1 \mathrm{H}), 5.44(\mathrm{~s}$, $1 \mathrm{H}), 3.57$ (s, 3H, broad), 2.00-1.80 (s, 2H, broad), $1.20(\mathrm{~s}, 3 \mathrm{H}$, $\mathrm{mm}), 1.01$ (s, 3H, mr), 0.82 (s, 3H, rr). The dispersity and molecular weights of the final products was determined by Gel Permeation Chromatography (GPC), $M_{\mathrm{n}}=1400 \mathrm{~g} \mathrm{~mol}^{-1}, D=1.76$.

General procedure for the copolymerisation of methyl methacrylate tetramer with deuterated methyl methacrylate $\left(\operatorname{MMAd}_{8}\right)^{14}$

For the copolymerisation in solution, MMA tetramer (1 g), butanone $(4 \mathrm{ml})$ and a stirring bar were charged into a $50 \mathrm{~mL}$ round bottom flask. Nitrogen was purged in the flask for $30 \mathrm{~min}$. Subsequently, the $\operatorname{MMAd}_{8}(2 \mathrm{~g})$ and a solution of 2,2'azobis(2-methylpropionitrile) (AIBN, $1 \mathrm{~mol} \%$ relative to monomer) in butanone, both previously deoxygenated for 15 min, were added. A deoxygenated stock solution of CoBF in butanone was also prepared. When CoBF was used in the experiment, the appropriate amount $(40 \mathrm{ppm}$ relative to monomer) of the stock solution was added in the round bottom flask. The reaction was heated at $60^{\circ} \mathrm{C}$, under a nitrogen atmosphere and stirred for 24 hours.

\section{General procedure for the copolymerisation of methacrylic macromonomers with acrylic monomers in solution}

For a standard copolymerisation in solution at $20 \%$ solids content, toluene, macromonomer and a stirring bar were charged into a $50 \mathrm{~mL}$ round bottom flask and the flask was purged with nitrogen for $30 \mathrm{~min}$. Subsequently, the second monomer and a solution of tert-butyl peroxy-2-ethylhexanoate (Trigonox-21s, $0.5 \mathrm{~mol} \%$ of the second monomer) in toluene (same volume with the second monomer) were added, previously deoxygenated for $30 \mathrm{~min}$. The reaction was heated under nitrogen for 18 hours. The number average molecular weight of each block was calculated by analysing the ${ }^{1} \mathrm{H}$ NMR and SEC spectra.

\section{Results and discussion}

\section{Synthesis of methacrylic macromonomers via catalytic chain transfer polymerisation}

Macromonomers of poly(methyl methacrylate) (pMMA), poly (butyl methacrylate) (pBMA), poly(benzyl methacrylate) (pBzMA) and poly(lauryl methacrylate) (pLMA) were synthesized using CCTP, with targeted molecular weights, ranging from 200 to $16700 \mathrm{~g} \mathrm{~mol}^{-1}$. Two different catalysts were selected according to their solubility in the monomer. In the polymerisation of MMA, CoBF was used, whereas the more hydrophobic $\mathrm{Co}(\mathrm{MePh}) \mathrm{BF}$ was used for the polymerisation of BMA, BzMA and LMA (Table 1). In all reactions, $1 \mathrm{~mol} \%$ of initiator to monomer and $1 / 1 \mathrm{v} / \mathrm{v}$ solvent to monomer were used. Moreover, the amount of catalyst was varied depending on the targeted molecular weight of the polymer desired.
Table 1 Methacrylic monomers and catalysts used in CCTP. Polymers of various $\mathrm{DP}_{\mathrm{n}}$, determined by GPC, were synthesised and used for this work

\begin{tabular}{llllr}
\hline Monomer & Catalyst & \multicolumn{2}{l}{$\begin{array}{l}\text { Number average degree of } \\
\text { polymerisation }\left(\mathrm{DP}_{\mathrm{n}}\right)\end{array}$} \\
\hline MMA & CoBF & 2 & 4 & 14 \\
BMA & Co(MePh)BF & 24 & & \\
BzMA & Co(MePh)BF & 47 & \multicolumn{1}{l}{18} \\
LMA & Co(MePh)BF & 12 & \\
\hline
\end{tabular}

The products were characterized by ${ }^{1} \mathrm{H}$ NMR and MALDI-ToF MS. Their NMR spectra were used to determine the $\mathrm{DP}_{\mathrm{n}}$, monitor conversion and confirm the presence of vinyl peaks from the propenyl end group, for instance for pLMA, at 6.19 and $5.46 \mathrm{ppm}$ (ESI Fig. 2a $\dagger$ ). MALDI-ToF was used to further demonstrate end group fidelity, which confirmed that the macromonomers have two distinct and characteristic terminal groups, a hydrogen atom at the $\alpha$-chain end and a vinyl group at their $\omega$-terminal.

It is noted that the lauryl methacrylate was used as purchased and is actually a mixture of $\mathrm{C}_{12}$ and $\mathrm{C}_{14}$ methacrylates (77\% and $23 \%$ ), presumably arising from the alkyl chain being
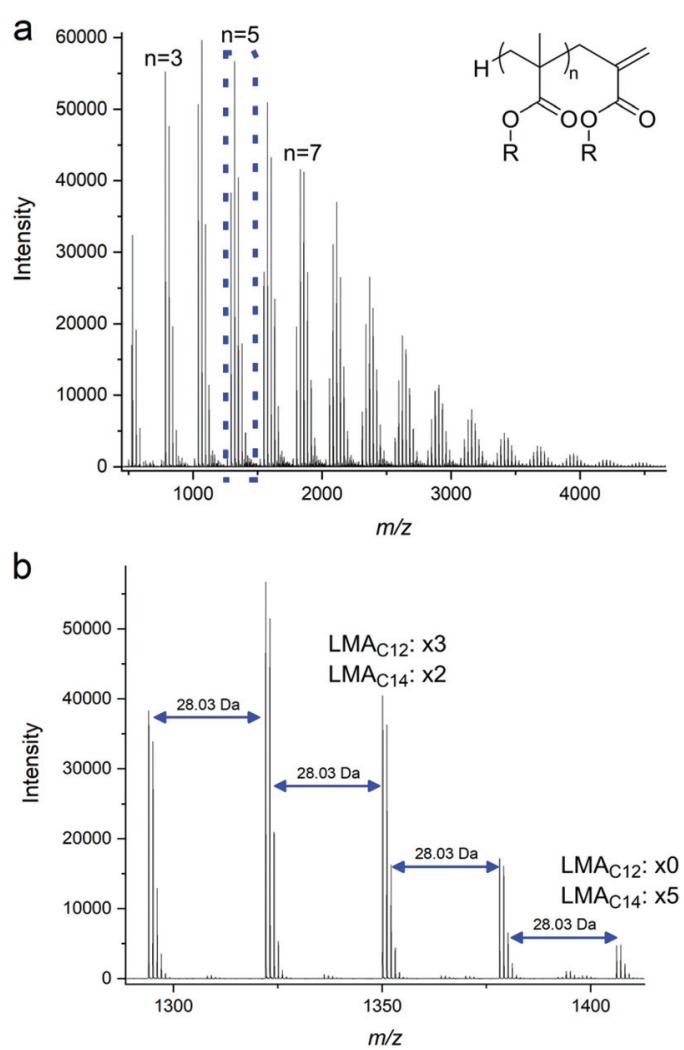

Fig. 1 (a) MALDI-ToF spectrum of the $\mathrm{pLMA}_{6}$ macromonomer as synthesized via CCTP. The distribution of the peaks is partly due to the existence of the two different monomers. (b) Expansion of the MALDI-ToF spectrum (a) in the $1250-1450 \mathrm{~m} / \mathrm{z}$ range, showing the mass difference of $28.03 \mathrm{~m} / \mathrm{z}$ due to the occurrence of the C14 together with the $\mathrm{C} 12$ monomer. 
derived from the hydrolysis of natural oils prior to transesterification with MMA. This mixture was considered to be acceptable for the purposes of this study and although difficult to see by NMR is clear from GC of the monomer and MALDI-ToF MS of the products, as shown in ESI Fig. $2 \mathrm{~b} \dagger$ and Fig. 1 respectively.

Size-exclusion chromatography (SEC) was used for the characterization of all products. Typical examples are shown for the synthesis of pLMA (ESI Fig. $3 \dagger$ ) as prepared with Co (MePh)BF as a catalyst. Molecular weight data from GPC is given in ESI Table 1. $\dagger$

Increasing the concentration of the cobalt catalyst in the reaction results in a lowering of the molecular weight of the product as in conventional chain transfer. ${ }^{21}$

The effective chain transfer activity $\left(C_{\mathrm{s}}^{\mathrm{E}}\right)$ of the catalysts, measured at high conversions, used in the CCTP of pLMA was measured using the Mayo equation (eqn (1)), where $\mathrm{DP}_{\mathrm{n}}$ is the number average degree of polymerisation in the presence of the CTA, $\mathrm{DP}_{\mathrm{n}}^{0}$ the number average degree of polymerisation in the absence of the CTA, [S] the concentration of CTA and [M] the concentration of the monomer.

$$
\frac{1}{\mathrm{DP}_{\mathrm{n}}}=\frac{1}{\mathrm{DP}_{\mathrm{n}}^{0}}+C_{\mathrm{s}}^{\mathrm{E}} \frac{[\mathrm{S}]}{[\mathrm{M}]}
$$

The activity of the relatively hydrophobic catalyst $\mathrm{Co}(\mathrm{MePh})$ $\mathrm{BF}$ for the polymerisation of LMA gave $C_{\mathrm{s}}^{\mathrm{E}}=1700$. Note that this is lower than the $C_{\mathrm{s}}^{\mathrm{E}}$ of $\mathrm{CoBF}$ for the polymerisation of
MMA, which is reported as $\approx 30000 .^{21}$ Thus, when the targeted $M_{\mathrm{n}}$ of pLMA was approximately 2000, 40 ppm of $\mathrm{Co}(\mathrm{MePh}) \mathrm{BF}$ was used, whereas the same ratio of CoBF is required only when a mixture of MMA dimer and trimer is targeted.

\section{Copolymerisation of methacrylic macromonomers with MMAd $_{8}$}

In an earlier report, we reported on the mechanism of the addition fragmentation by addition of MMA tetramer $\left(\mathrm{MMA}_{4}\right.$ as produced by CCTP of MMA followed by isolation by distillation) to further polymerisation reactions of BMA. ${ }^{14}$ Using MALDI-ToF, we showed that following the addition of a methacrylic radical to $\mathrm{MMA}_{4}$, the only detectable reaction pathway was $\beta$-scission (fragmentation) of the radical adduct, with no chain transfer to cobalt detected or copolymerisation. Herein, we repeated these reactions, substituting BMA with fully deuterated MMA $\left(\mathrm{MMAd}_{8}\right)$ given advances in analytical techniques since the original studies to reaffirm this in relation to the present study. As it is always preferable to remove oxygen from a free radical polymerisation prior to the reaction we monitoring this with an oxygen concentration probe (FireStingGO $\mathrm{G}_{2}$ optical probe utilising quenching of oxygen in the NIR), we found that the time taken to deoxygenate reactants varied from 1 to 30 minutes, depending on their physical state (ESI Fig. $4 \dagger$ ).

The molecular weight of $\operatorname{MMAd}_{8}=108.15 \mathrm{~g} \mathrm{~mol}^{-1}$ which allows for differentiation from the MMA macromonomer in
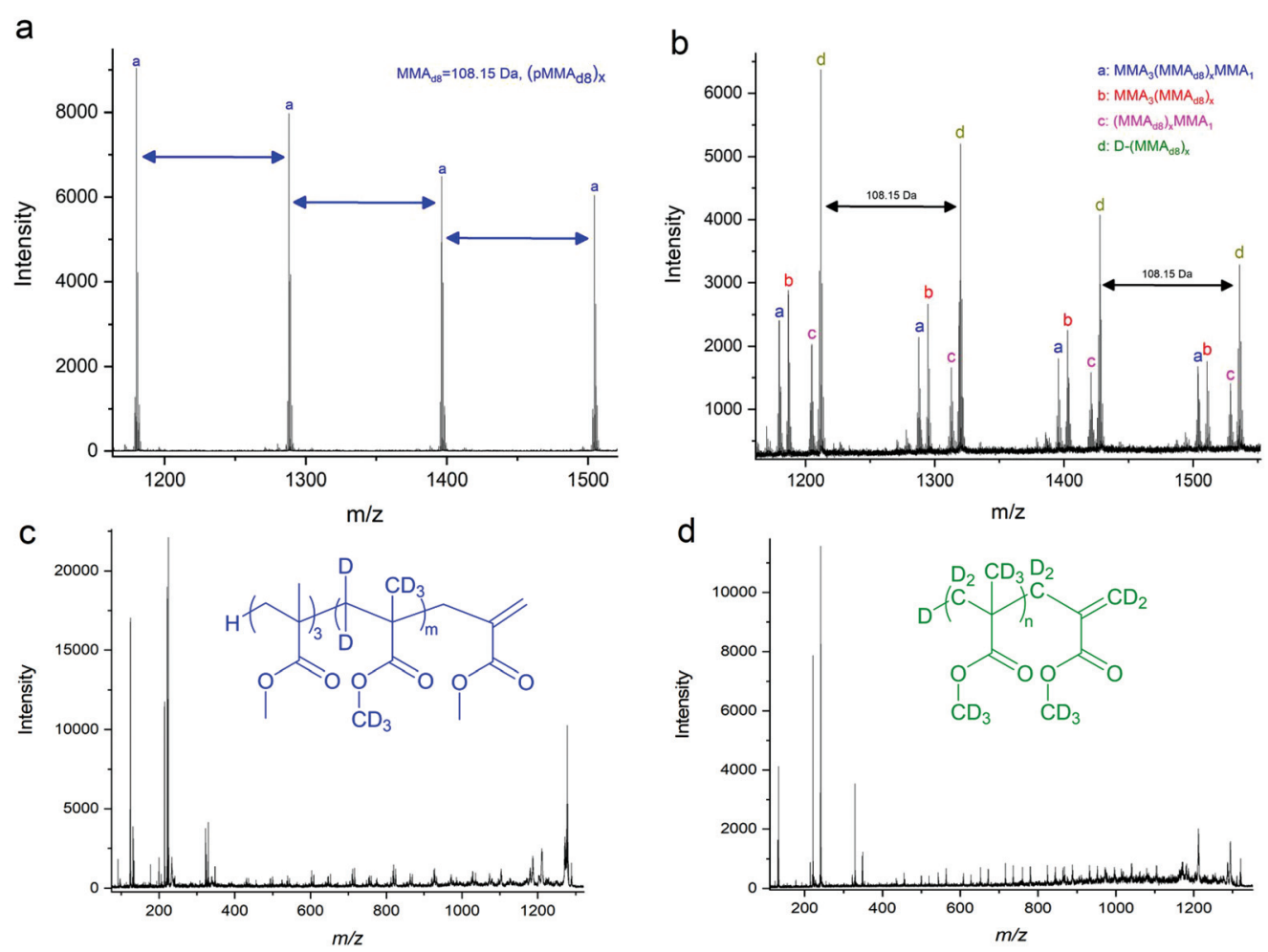

Fig. 2 (a) Expansion of the full MALDI-ToF spectrum, ESI Fig. $6 a$, $\uparrow$ of the copolymerisation of pMMA $\mathrm{A}_{4}$ with $M M A d_{8}$ in the $1150-1550 \mathrm{~m} / z$ range. (b) Expansion of the full MALDI-ToF spectrum, ESI Fig. $6 \mathrm{~b}, \uparrow$ of the copolymerisation of $\mathrm{pMMA}_{4}$ with $\mathrm{MMAd}_{8}$ in the presence of CoBF in the $1150-1550$ $\mathrm{m} / \mathrm{z}$ range. (c) MALDI-ToF/ToF of peak "a" in Fig. $2 \mathrm{~b}$ showing the backbone cleavages. (d) MALDI-ToF/ToF of peak " $\mathrm{d}$ " in Fig. $2 \mathrm{~b}$ showing the backbone cleavages. 
MALDI-ToF MS. Four products are observed in the MALDI-ToF MS spectra (Fig. 2a and b), in the presence of CoBF, (Fig. 2b). In order to achieve more detailed information of the products MALDI-ToF/ToF was also used, Fig. 2c and d. This technique provides the fragmentation patterns of the polymers, allowing for the exploration of the arrangement of the monomeric units in the products. Thus, analysing the peak at $m / z=1319.857$ (d in Fig. 2b) using MALDI-ToF/ToF, Fig. 2d, the highest magnitude signal originates from products of the general formula $\mathrm{D}$ $\left(\operatorname{MMAd}_{8}\right)_{x}$, which would be the product expected from the CCTP of MMAd $_{8}$ in the absence of $\mathrm{MMA}_{4}$. However, smaller peaks are also apparent from products that contain 1 MMA, 4 MMA and 3 MMA units with an absence of products containing 2 MMA monomers. These are derived from $\mathrm{MMA}_{3}\left(\mathrm{MMAd}_{8}\right)_{x} \mathrm{MMA}_{1}, \mathrm{MMA}_{3}\left(\operatorname{MMAd}_{8}\right)_{x}$ and $\mathrm{H}\left(\mathrm{MMAd}_{8}\right)_{x} \mathrm{MMA}_{1}$ which arise from fragmentation and reinitiation. This supports

Table 2 Copolymerisation of $M A$ with $p M M A_{x} .2 \mathrm{ml}$ of $M A$ were used in the reactions with $\mathrm{pMMA}$ and $4 \mathrm{ml}$ with $\mathrm{pMMA}_{4}$ and $\mathrm{pMMA}_{14}$

\begin{tabular}{|c|c|c|c|c|c|}
\hline Sample & Monomer & $\mathrm{pMMA}_{x}$ & $\begin{array}{l}\text { pMMA }_{x} \text { to } \\
\text { MA (mol\%) }\end{array}$ & $M_{\mathrm{n}}\left(\mathrm{g} \mathrm{mol}^{-1}\right)$ & $Ð$ \\
\hline 1 & MA & - & - & 25600 & 2.91 \\
\hline 2 & MA & $\mathrm{pMMA}_{2}$ & 0.4 & 23400 & 3.21 \\
\hline 3 & MA & $\mathrm{pMMA}_{2}$ & 2.1 & 12600 & 2.11 \\
\hline 4 & MA & $\mathrm{pMMA}_{2}$ & 4.3 & 3600 & 1.60 \\
\hline 5 & MA & - & - & 37500 & 2.83 \\
\hline 6 & MA & $\mathrm{pMMA}_{4}$ & 0.2 & 33800 & 3.01 \\
\hline 7 & MA & $\mathrm{pMMA}_{4}$ & 1.1 & 23300 & 2.71 \\
\hline 8 & MA & $\mathrm{pMMA}_{4}$ & 2.2 & 16400 & 2.34 \\
\hline 9 & MA & $\mathrm{pMMA}_{4}$ & 4.3 & 5100 & 2.39 \\
\hline 10 & MA & $\mathrm{pMMA}_{14}$ & 0.6 & 30100 & 2.12 \\
\hline
\end{tabular}

the observed results from our previously published work, that $\beta$-scission is the predominant reaction pathway of the macromonomer radical adduct under these reaction conditions, Fig. 2 and ESI Table $2 . \dagger^{18}$

\section{Copolymerisation of methacrylic macromonomers with acrylates}

Following from the copolymerisation with methacrylates, we investigated the effect of polymerisation of acrylic monomers in the presence these macromonomers noting acrylates have a higher propagation rate constant than corresponding methacrylates, $k_{\mathrm{p}}$. Initially, MA was used for copolymerisation with MMA dimer. The molar ratio of $\left[\mathrm{MMA}_{2}\right]$ to $[\mathrm{MA}]$ was varied between 0 and $4.3 \mathrm{~mol} \%$ which had a marked effect on the molecular weight of the final product, Table 2 and Fig. 3a. MALDI-ToF MS was used to analyse the products and the results confirmed that the copolymerisation of a MMA dimer with methyl acrylate leads to graft copolymers, Fig. $3 \mathrm{~d}^{33,34,36}$ According to Fig. 4a, grafted copolymers of pMA with 2, 3 and 4 units of MMA dimer are produced during the copolymerisation (ESI Table $3 \dagger$ ). Furthermore, pMA polymers with up to six MMA dimers per molecule were calculated in higher molecular weights of the same spectrum.

Distilled $\mathrm{MMA}_{4}$ macromonomer was studied in the copolymerisation with MA and the results compared with those obtained when using the equivalent MMA dimer, Fig. 3b and e. Interestingly, the chain length of the macromonomer affects the graft amount incorporated into the final product. The grafting density of $\mathrm{MMA}_{4}$ is limited to two per polymer chain, and the amounts of the copolymer $\mathrm{pMA}_{x}-b-\left(\mathrm{MMA}_{4}\right)_{1}$
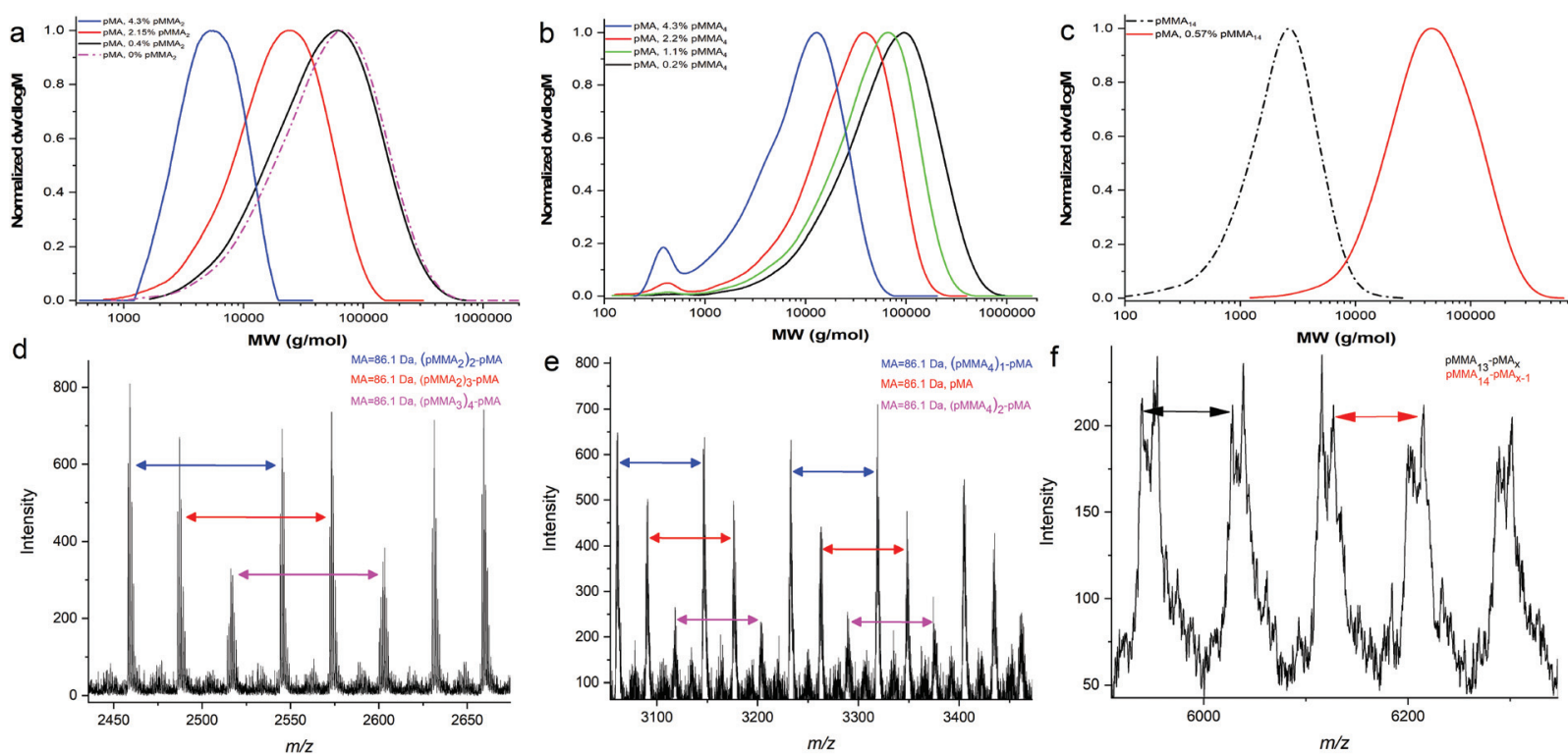

Fig. 3 (a) GPC results of the pMA homopolymer and the copolymerisation of MA with different amount of pMMA 2 . (b) GPC results of the copolymerisation of MA with different amount of $\mathrm{PMMA}_{4}$. (c) GPC results of the copolymerisation of MA with different amount of pMMA $\mathrm{A}_{14}$. (d) Expansion of the full MALDI-ToF spectrum of the copolymerisation of pMA with $\mathrm{MMA}_{2}$ (sample 4) in the $2430-2700 \mathrm{~m} / \mathrm{z}$ range. (e) Expansion of the full MALDI-ToF spectrum of the copolymerisation pMA with $\mathrm{MMA}_{4}$ (sample 9) in the 3050-3470 $\mathrm{m} / \mathrm{z}$ range. (f) Expansion of the MALDI-ToF spectrum of the copolymerisation of pMA with $\mathrm{pMMA}_{14}$ in the $5900-6350 \mathrm{~m} / \mathrm{z}$ range. 

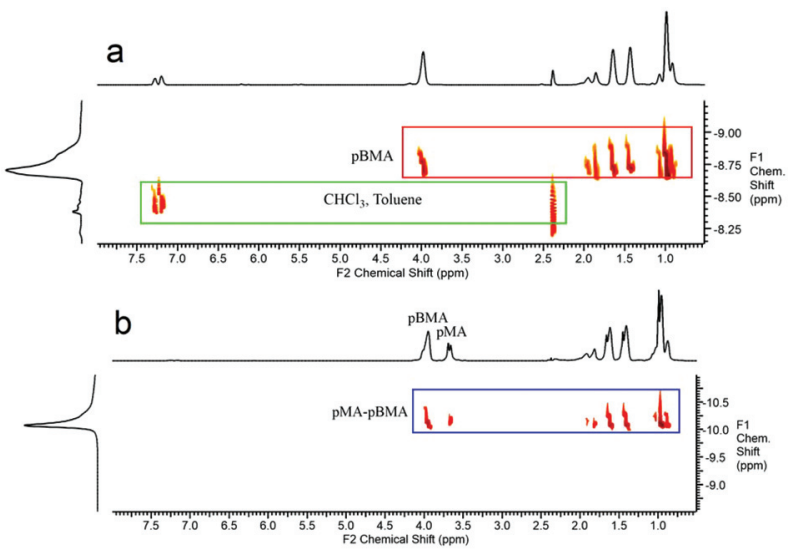

Fig. 4 (a) DOSY NMR of pBMA macromonomer. The peaks of the macromonomer and solvents have different diffusion constants. (b) DOSY NMR of the free radical polymerisation of MA in the presence of 3.3 mol\% pBMA macromonomer. The diffusion constant of the pure final product is different from that of the macromonomer.

and $\mathrm{pMA}_{x}$ homopolymer were detected in larger amounts relative to the graft copolymer.

Subsequently, the copolymerisation of $\mathrm{pMMA}_{14}$ with $\mathrm{MA}$ was carried out, Fig. 3c. The main peaks of the MALDI-ToF spectra indicate the formation of an end-capped diblock copolymer pMMA- $b$-pMA arising from a chain stopping reaction whereby a propagating PMA chain adds a PMMA macromonomer with subsequent termination occuring in preference to propagation. However, due to the small difference in the masses of the monomers it is not $100 \%$ certain if there is also graft copolymer in the product, Fig. $3 \mathrm{f}$.

In order to further investigate this copolymerisation reaction, a pBMA CCTP macromonomer was copolymerised with MA. The larger side group alkyl chain and the higher molecular weight of this macromonomer were chosen so as to help gain a better insight into this system. Methyl acrylate was polymerised in the presence of 0.26 and $3.3 \mathrm{~mol} \%$ of pBMA, under similar reaction conditions as described above, and a shift to higher molecular weight for the product observed (ESI Fig. 7 and Table $4 \dagger$ ). The DOSY NMR spectra of the macromonomer, Fig. 4a, when compared to the final product of the copolymerisation with MA, Fig. 4b, show distinct differences in the diffusion constants of the pBMA before and after copolymerisation. Moreover, all of the protons of the final product are aligned on the same region of the spectrum (same diffusion rate), indicating that they are part of the same molecule.

In order to further investigate the effect of the nature of the macromonomer, methyl acrylate (MA) was copolymerised with both poly(benzyl methacrylate) and poly(lauryl methacrylate) macromonomers, Fig. 5. Similarly, to previous results, a decrease of the $M_{\mathrm{n}}$ of the products with increasing macromonomer concentration is observed (Table 3 and ESI Table $5 \dagger$ ). However, interestingly, from MALDI-ToF analysis, only end-capped diblock copolymers were obtained, Fig. 5 and
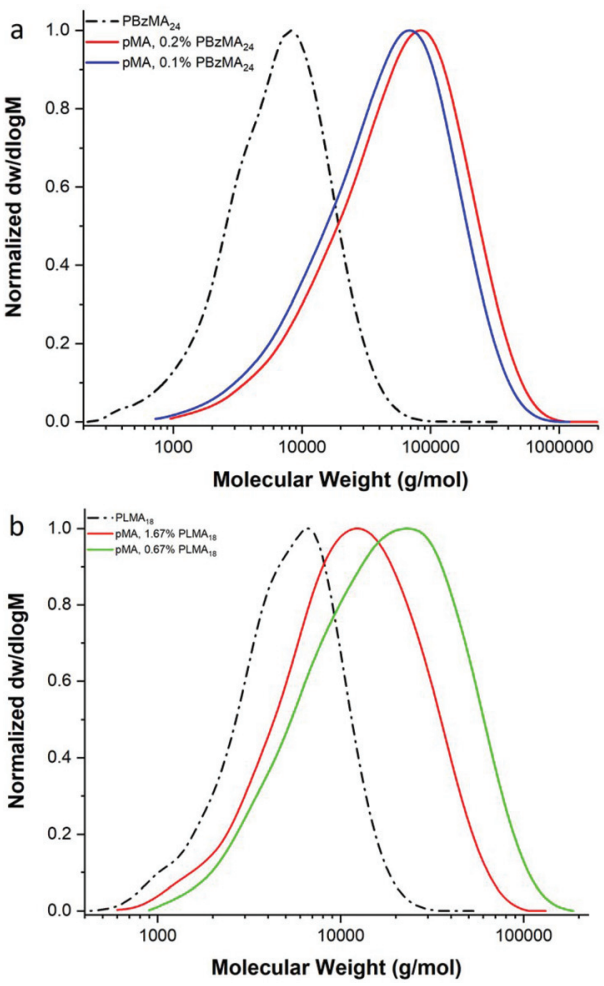

Fig. 5 GPC results of the free radical polymerisation of (a) MA with $0.1 \mathrm{~mol} \%$ and $0.2 \mathrm{~mol} \% \mathrm{pBzMA}_{24}$ and (b) MA with $0.67 \mathrm{~mol} \%$ and 1.67 mol\% $\mathrm{pLMA}_{18}$.

Table 3 Copolymerisation of $\mathrm{pLMA}_{18}$ with methyl acrylate

\begin{tabular}{|c|c|c|c|c|c|}
\hline Sample & Monomer & $\mathrm{pLMA}_{18}$ & $\begin{array}{l}\mathrm{pLMA}_{18} \text { to } \\
\text { MA (mol\%) }\end{array}$ & $M_{\mathrm{n}}\left(\mathrm{g} \mathrm{mol}^{-1}\right)$ & $Ð$ \\
\hline 1 & MA & - & - & 25600 & 2.91 \\
\hline 11 & MA & $\mathrm{pLMA}_{18}$ & 0.17 & 24500 & 3.93 \\
\hline 12 & MA & $\mathrm{pLMA}_{18}$ & 0.52 & 20000 & 3.76 \\
\hline 13 & MA & $\mathrm{pLMA}_{18}$ & 0.67 & 10700 & 2.27 \\
\hline 14 & MA & $\mathrm{pLMA}_{18}$ & 1.67 & 7600 & 2.05 \\
\hline 15 & MA & $\mathrm{pLMA}_{18}$ & 10 & 5500 & 1.72 \\
\hline
\end{tabular}

ESI Fig. $8 . \dagger$ The $77 \%$ to $23 \%$ ratio of the isomers of LMA is observed in the MALDI-ToF spectra of the diblock copolymer pLMA- $b$-pMA. The main peaks refer to end-capped pLMA $_{\mathrm{C} 12}$ macromonomer, as it is in the higher percentage. The 28 and $56 \mathrm{~m} / \mathrm{z}$ difference is due to block copolymers with a different number of the monomeric units, C12 or C14 LMA monomers, in the final product.

Finally, the methacrylic macromonomer pLMA was added to the free radical polymerisation of the more hydrophobic acrylate, butyl acrylate (BA). Similarly, the macromonomer acts as terminating species via an end-capping event as opposed to a monomer, leading to the block copolymer pLMA- $b$-pBA as opposed to graft copolymers, ESI Table 6 and Fig. $10 . \dagger$

In the case of the pLMA with higher steric hindrance, only block copolymers result via this end-capping by the macromonomer to the macroradical pMA (Fig. 6). This suggests that 

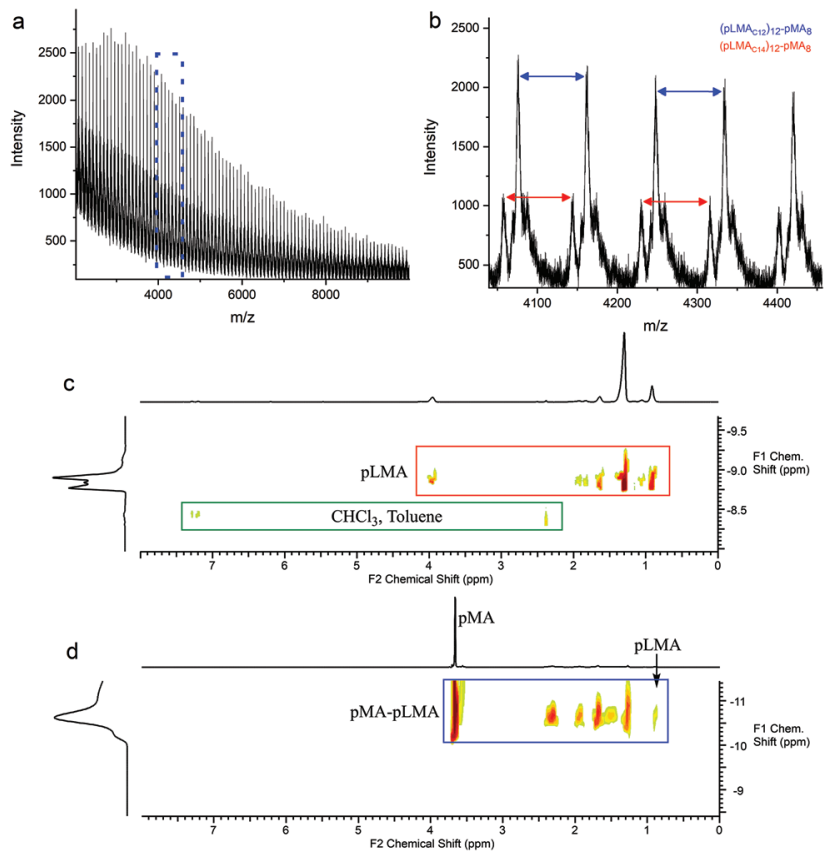

Fig. 6 (a) Full MALDI-ToF spectra of the copolymerisation of MA with pLMA macromonomer, sample 11, showing the diblock copolymer formation via end-capping. (b) Expansion of the MALDI-ToF (a) of the in the $4050-4450 \mathrm{~m} / \mathrm{z}$ range. (c) DOSY NMR of pLMA macromonomer. The peaks of the macromonomer and solvents have different diffusion constants. (d) DOSY NMR of the free radical polymerisation of MA in the presence of 0.17 mol\% pLMA macromonomer, sample 11. The diffusion constant of the pure final product is different from that of the macromonomer. during the copolymerisation of a methacrylic macromonomer from CCTP and acrylic monomers, an increase of the molecular weight of the macromonomer, and also of the ester side chain length, reduces the likelihood of obtaining graft copolymers (Scheme 2). On the contrary, if the steric hindrance of the macromonomer is high, it results in an end-capping reaction of the propagating polyacrylate radical and diblock copolymers are the only product.

Thus diblock copolymers of methacrylic and acrylic monomers can be synthesised using the appropriate methacrylic macromonomer as derived from CCTP. Further studies have already been conducted in order to optimize the conditions in solution, as this is a highly useful and scalable technique to combine the properties of different monomers, in relatively facile synthetic conditions, applicable to scale-up and application.

\section{Conclusions}

In summary, we present a reproducible, easy to use and scalable method of producing block copolymers of different types of methacrylate/acrylate monomers with relatively broad dispersities of each block. Moreover, the significant effect of the size of CCTP pMMA macromonomers in the grafting density during their copolymerisation with methyl acrylate was demonstrated. Methacrylic macromonomers with larger side ester chains were shown to end-cap the acrylic macroradical leading to $\mathrm{AB}$ diblock copolymers. During the diblock formation, no by products were produced, although the high polydispersity of each block, making this procedure versatile for the synthesis of materials without the presence of sulphur substances or transition metals.

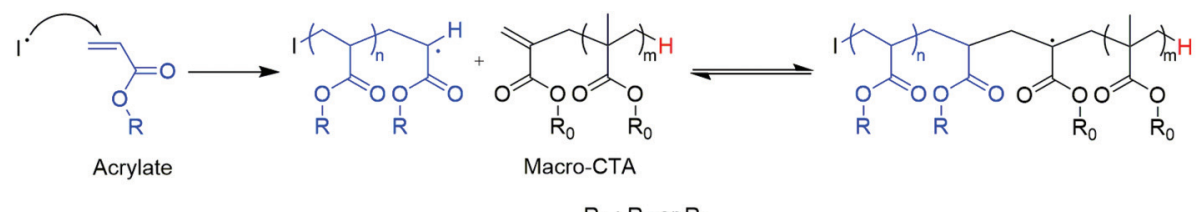

$\mathrm{R}_{0}: \mathrm{R}_{1}$ or $\mathrm{R}_{2}$

$R_{1}$ : Methacrylate with small ester group (Methyl) and low molecular weight

$\mathrm{R}_{2}$ : Methacrylate with large ester group (Butyl, Benzyl or Lauryl) and high molecular weight

a) Copolymerisation leading to graft copolymers

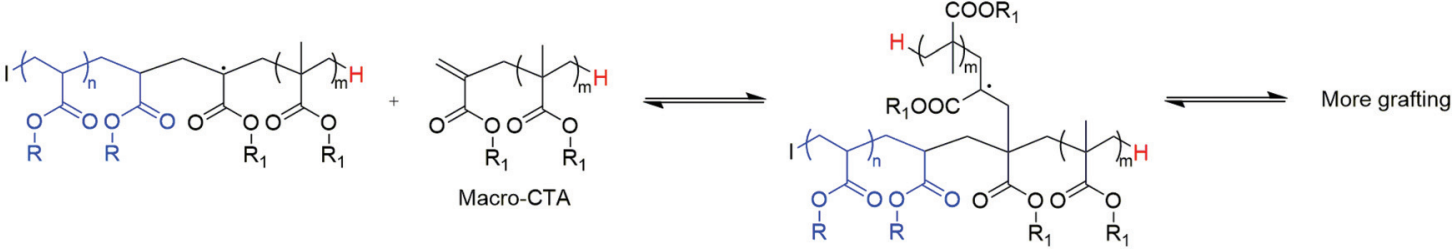

b) End-capping leading to diblock copolymers

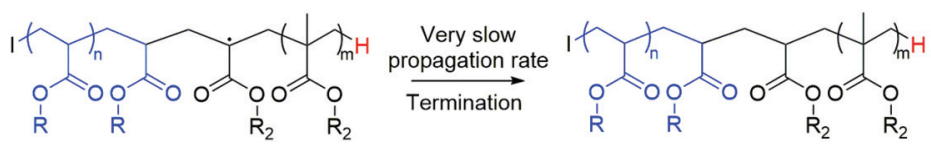

Scheme 2 Schematic presentation of the proposed routes of the free radical polymerisation of acrylates in the present of methacrylic macromonomers leading to graft or diblock copolymers. 


\section{Conflicts of interest}

There are no conflicts to declare.

\section{Acknowledgements}

We are grateful to the Polymer Characterisation RTP and Dr Daniel Lester (University of Warwick) for providing use of SEC equipment. We thank Lubrizol (GP, CJA), Unilever (SE), DSM (AS) and Syngenta (RIW) as well as the University of Warwick and the EPSRC Centre for Doctoral Training in Molecular Analytical Science, grant number EP/L015307/1 with additional funding granted by Syngenta and AstraZeneca (JT) for studentship funding.

The raw data for all information presented in this paper can be accessed from The University of Warwick repository at https://wrap.warwick.ac.uk/127874.

\section{Notes and references}

1 D. J. Krasznai, T. F. L. McKenna, M. F. Cunningham, P. Champagne and N. M. B. Smeets, Polym. Chem., 2012, 3, 992-1001.

2 C. J. Atkins, G. Patias, J. S. Town, A. M. Wemyss, A. M. Eissa, A. Shegiwal and D. M. Haddleton, Polym. Chem., 2019, 10, 646-655.

3 G. Nurumbetov, N. Engelis, J. Godfrey, R. Hand, A. Anastasaki, A. Simula, V. Nikolaou and D. M. Haddleton, Polym. Chem., 2017, 8, 1084-1094.

4 D. M. Haddleton, E. Depaquis, E. J. Kelly, D. Kukulj, S. R. Morsley, S. A. F. Bon, M. D. Eason and A. G. Steward, J. Polym. Sci., Part A: Polym. Chem., 2001, 39, 23782384.

5 A. Anastasaki, C. Waldron, V. Nikolaou, P. Wilson, R. McHale, T. Smith and D. M. Haddleton, Polym. Chem., 2013, 4, 4113-4119.

6 A. H. Soeriyadi, G. Z. Li, S. Slavin, M. W. Jones, C. M. Amos, C. R. Becer, M. R. Whittaker, D. M. Haddleton, C. Boyer and T. P. Davis, Polym. Chem., 2011, 2, 815-822.

7 N. M. B. Smeets, Eur. Polym. J., 2013, 49, 2528-2544.

8 L. Nurmi, J. Lindqvist, R. Randev, J. Syrett and D. M. Haddleton, Chem. Commun., 2009, 2727-2729.

9 J. Krstina, G. Moad, E. Rizzardo, C. L. Winzor, C. T. Berge and M. Fryd, Macromolecules, 1995, 28, 5381-5385.

10 C. L. Moad, G. Moad, E. Rizzardo and S. H. Thang, Macromolecules, 1996, 29, 7717-7726.

11 D. G. Hawthorne, R. L. Laslett, E. Rizzardo and D. H. Solomon, J. Macromol. Sci., Part A, 1986, 23, 839-852.

12 N. G. Engelis, A. Anastasaki, G. Nurumbetov, N. P. Truong, V. Nikolaou, A. Shegiwal, M. R. Whittaker, T. P. Davis and D. M. Haddleton, Nat. Chem., 2017, 9, 171-178.

13 B. Yamada, P. Zetterlund and E. Sato, Utility of propenyl groups in free radical polymerization: Effects of steric hin- drance on formation and reaction behavior as versatile intermediates, 2006.

14 D. M. Haddleton, D. R. Maloney and K. G. Suddaby, Macromolecules, 1996, 29, 481-483.

15 D. M. Haddleton, D. R. Maloney, K. G. Suddaby Adam Clarke and S. N. Richards, Polymer, 1997, 38, 6207-6217.

16 T. Davis, D. Kukulj, D. M. Haddleton and D. R. Maloney, Cobalt-mediated free-radical polymerization of acrylic monomers, 1995.

17 D. M. Haddleton, D. R. Maloney, K. G. Suddaby, A. V. G. Muir and S. N. Richards, Macromol. Symp., 1996, 111, 37-46.

18 D. M. Haddleton, D. R. Maloney and K. G. Suddaby, Macromolecules, 1996, 29, 481-483.

19 D. M. Haddleton, M. C. Crossman, K. H. Hunt, C. Topping, C. Waterson and K. G. Suddaby, Macromolecules, 1997, 30, 3992-3998.

20 A. Gridnev, J. Polym. Sci., Part A: Polym. Chem., 2000, 38, 1753-1766.

21 J. P. A. Heuts and N. M. B. Smeets, Polym. Chem., 2011, 2, 2407-2423.

22 S. Slavin, E. Khoshdel and D. M. Haddleton, Polym. Chem., 2012, 3, 1461-1466.

23 Q. Zhang, S. Slavin, M. W. Jones, A. J. Haddleton and D. M. Haddleton, Polym. Chem., 2012, 3, 1016-1023.

24 D. M. Haddleton, E. Depaquis, E. J. Kelly, D. Kukulj, S. R. Morsley, S. A. F. Bon, M. D. Eason and A. G. Steward, J. Polym. Sci., Part A: Polym. Chem., 2001, 39, 2378-2384.

25 K. G. Suddaby, D. M. Haddleton, J. J. Hastings, S. N. Richards and J. P. O'Donnell, Macromolecules, 1996, 29, 8083-8091.

26 I. Schreur-Piet and J. P. A. Heuts, Polym. Chem., 2017, 8, 6654-6664.

27 G. E. Roberts, T. P. Davis, J. P. A. Heuts and G. E. Ball, Macromolecules, 2002, 35, 9954-9963.

28 N. G. Engelis, A. Anastasaki, R. Whitfield, G. R. Jones, E. Liarou, V. Nikolaou, G. Nurumbetov and D. M. Haddleton, Macromolecules, 2018, 51, 336-342.

29 A. Shegiwal, A. M. Wemyss, M. A. J. Schellekens, J. de Bont, J. Town, E. Liarou, G. Patias, C. J. Atkins and D. M. Haddleton, J. Polym. Sci., Part A: Polym. Chem., 2019, 57, E1-E9.

30 L. Hutson, J. Krstina, C. L. Moad, G. Moad, G. R. Morrow, A. Postma, E. Rizzardo and S. H. Thang, Macromolecules, 2004, 37, 4441-4452.

31 S. Beuermann, M. Buback, T. P. Davis, R. G. Gilbert, R. A. Hutchinson, O. F. Olaj, G. T. Russell, J. Schweer and A. M. van Herk, Macromol. Chem. Phys., 1997, 198, 15451560.

32 M. Buback and C. H. Kurz, Macromol. Chem. Phys., 1998, 199, 2301-2310.

33 P. Cacioli, D. G. Hawthorne, R. L. Laslett, E. Rizzardo and D. H. Solomon, J. Macromol. Sci., Part A, 1986, 23, 839-852.

34 K. J. Abbey, D. L. Trumbo, G. M. Carlson, M. J. Masola and R. A. Zander, J. Polym. Sci., Part A: Polym. Chem., 1993, 31, 3417-3424. 
35 L. M. Muratore, K. Steinhoff and T. P. Davis, J. Mater. Chem., 1999, 9, 1687-1691.

36 B. Yamada, F. Oku and T. Harada, J. Polym. Sci., Part A: Polym. Chem., 2003, 41, 645-654.
37 B. Yamada and S. Kobatake, Prog. Polym. Sci., 1994, 19, 1089-1131.

38 D. Colombani and P. Chaumont, Prog. Polym. Sci., 1996, 21, 439-503. 